\title{
Mechanisms and functions of endocytosis in T cells
}

\author{
John C. Charpentier and Philip D. King ${ }^{*}$ (D)
}

\begin{abstract}
Once thought of primarily as a means to neutralize pathogens or to facilitate feeding, endocytosis is now known to regulate a wide range of eukaryotic cell processes. Among these are regulation of signal transduction, mitosis, lipid homeostasis, and directed migration, among others. Less well-appreciated are the roles various forms of endocytosis plays in regulating $\alpha \beta$ and, especially, $\gamma \delta T$ cell functions, such as T cell receptor signaling, antigen discovery by trogocytosis, and activated cell growth. Herein we examine the contribution of both clathrin-mediated and clathrinindependent mechanisms of endocytosis to T cell biology.
\end{abstract}

Keywords: Endocytosis, Macropinocytosis, T lymphocytes, TCR signaling, Cell growth

\section{Background}

Endocytosis, the generation of internal membranes from the plasma membrane by invagination and vesicle scission, facilitates a range of diverse cellular processes in eukaryotes. In addition to enabling the internalization of extracellular macromolecules, endocytosis permits the compartmentalization of chemistry within cells. Coevolution of endocytosis and cellular endosymbiosis, the state of one cell living mutualistically within another, may have significantly contributed to the complexity of eukaryotic cells [1]. Functions regulated at least in part by endocytosis include: signal transduction, membrane composition, mitosis, adhesion, lipid homeostasis, motility, and cell morphogenesis. Distinct forms of endocytosis have evolved in eukaryotes, with clathrin-mediated endocytosis (CME) being the most well-described and universal type. Other forms are limited to and adapted for specific cell types or lineage states.

Whereas endocytic regulation of some cellular functions, such as immune surveillance, has been extensively described in some immune cell types (such as dendritic

*Correspondence: kingp@umich.edu

Department of Microbiology and Immunology, University of Michigan Medical School, 6606 Med Sci II, 1150 West Medical Center Drive, Ann Arbor, MI 48109-5620, USA cells and macrophages), its functional importance in $\mathrm{T}$ cells has been less appreciated. This review will discuss the role of endocytosis in the regulation of $\mathrm{T}$ cell function.

\section{Forms of endocytosis}

\section{Clathrin-mediated endocytosis}

Endocytic pathways are often broadly classified by their dependence on the hexamer protein clathrin. This is in part due to the historical primacy of the characterization of clathrin-mediated endocytosis (CME) in 1976 but also in acknowledgement of its role as the primary endocytic route for cellular housekeeping functions [65]. In CME, the assembly of clathrin triskelions on spherical membrane buds drives the formation of clathrin-coated pits (CCPs) $60-120 \mathrm{~nm}$ in diameter [66]. CCPs progress through a series of well-defined morphological intermediates to form clathrin-coated vesicles (CCVs) upon scission from the plasma membrane. Post-scission, the clathrin assemblies disintegrate, additional machinery is removed by uncoating factors, and uncoated vesicles deliver their contents to endosomes by fusion [67]. CCVs can be further classified by the differential recruitment of over 50 adaptor and accessory proteins, as well as by the identity of their lipid and protein cargoes [66]. original author(s) and the source, provide a link to the Creative Commons licence, and indicate if changes were made. The images or other third party material in this article are included in the article's Creative Commons licence, unless indicated otherwise in a credit line to the material. If material is not included in the article's Creative Commons licence and your intended use is not permitted by statutory regulation or exceeds the permitted use, you will need to obtain permission directly from the copyright holder. To view a copy of this licence, visit http://creativecommons.org/licenses/by/4.0/. The Creative Commons Public Domain Dedication waiver (http://creativecommons.org/publicdomain/zero/1.0/) applies to the data made available in this article, unless otherwise stated in a credit line to the data. 
For many years, the term "receptor-mediated endocytosis" was used synonymously with CME. It is now appreciated, however, that removal of many plasmalemmal receptors is accomplished by multiple mechanisms that do not require clathrin. Consequently, this usage is discouraged and a more descriptive schema-classification of endocytic routes by the identity of vesicular membrane components and cargoes-has been adopted.

\section{Clathrin-independent mechanisms of endocytosis}

Some cellular functions, such as response to high intensity stimuli and directed migration, require rapid endocytosis of large patches of membrane. These events require membrane fluxes on the millisecond-to-second scale, which CME is not sufficient for [68]. In recent decades, a number of mechanisms of clathrin-independent endocytosis (CIE) have been discovered and characterized, some of which enable rapid, bulk internalization of membrane or otherwise facilitate acute responses. Relative to CME, flux through CIE pathways accounts for only a small proportion of endocytic events in mammalian cells [69]. Our present knowledge of CIE is chiefly limited by the lack of validated, path-specific molecular determinants and cargoes, as well as the existence of shared machinery between pathways and these factors confound interpretation of experimental results. Nevertheless, salient features of each form have been experimentally elucidated.

Building on the classification of Doherty and McMahon (2009), CIE includes: caveolae-dependent endocytosis, clathrin-independent carrier/GPI-AP-enriched early endosomal compartment (CLIC/GEEC) pathway endocytosis, flotillin-dependent endocytosis, interleukin 2 receptor beta (IL-2R $\beta$ ) pathway endocytosis, Arf6dependent endocytosis, phagocytosis, macropinocytosis, fast endophilin-mediated endocytosis, activity-dependent bulk endocytosis (ADBE), ultra-fast endocytosis (UFE), and massive endocytosis (MEND) [70]. Each of these forms of endocytosis, the essential features of which are summarized in Table 1, will be discussed briefly.

Caveolae-dependent endocytosis is characterized by its requirement for the integral membrane protein caveolin-1 and a small number of adaptor proteins of the cavin family (four in mammals), as well as by its sensitivity to glycosphingolipid depletion $[13,71]$. Caveolae, so named for their resemblance to

Table 1 Modes of endocytosis and their salient features

\begin{tabular}{|c|c|c|c|c|c|c|}
\hline & Actin-dependent & $\begin{array}{l}\text { Scale (vesicle } \\
\text { diameter) }\end{array}$ & Canonical cargoes & $\begin{array}{l}\text { Cholesterol- } \\
\text { dependent }\end{array}$ & $\begin{array}{l}\text { Dynamin- } \\
\text { dependent }\end{array}$ & $\begin{array}{l}\text { Cell type first } \\
\text { described in }\end{array}$ \\
\hline $\begin{array}{l}\text { Clathrin-dependent } \\
\text { endocytosis }\end{array}$ & $\begin{array}{l}\text { Depends on cell } \\
\text { type [2] }\end{array}$ & $35-200$ nm [3] & $\operatorname{Tfr}[4]$ & Yes [5] & Yes $[6,7]$ & A. aegypti oocytes [8] \\
\hline $\begin{array}{l}\text { Caveolae-dependent } \\
\text { endocytosis }\end{array}$ & Yes [9-11] & $50-80$ nm [12] & Unclear & Yes [13] & Yes [14] & $\begin{array}{l}\text { Murine gall bladder } \\
\text { epithelium [15] }\end{array}$ \\
\hline $\begin{array}{l}\text { CLIC/GEEC pathway } \\
\text { endocytosis }\end{array}$ & Yes $[16,17]$ & $\begin{array}{l}\text { Tubulovesicular, } \\
40 \mathrm{~nm} \text { width [18] }\end{array}$ & CTxB, CD44 [19] & Yes [16] & No [20] & COS, CHO cells [21] \\
\hline $\begin{array}{l}\text { Flotillin-dependent } \\
\text { endocytosis }\end{array}$ & Unclear [22] & Unclear & Unclear & Yes [23] & Unclear & HeLa cells [24] \\
\hline $\begin{array}{l}\text { IL-2Rß pathway } \\
\text { endocytosis }\end{array}$ & Yes [25] & $50-100 \mathrm{~nm}[25,26]$ & IL-2Rß [26] & Yes $[27,28]$ & Yes [29] & $\begin{array}{l}\text { IARC } 301.5, Y T 2 C 2, \\
\text { CIAC cells [30] }\end{array}$ \\
\hline $\begin{array}{l}\text { Arf6-dependent } \\
\text { endocytosis }\end{array}$ & Yes [31] & $60-200 \mathrm{~nm}$ & MHC-I, CD59 [32] & Yes [32] & Unclear & CHO cells [33] \\
\hline Phagocytosis & Yes $[34,35]$ & $0.5-3 \mu \mathrm{m}[36-39]$ & Microbial pathogens & Yes $[40,41]$ & Yes [42] & $\begin{array}{l}\text { Ranine phagocytes } \\
\text { [43] }\end{array}$ \\
\hline $\begin{array}{l}\text { Fast endophilin- } \\
\text { mediated endocyto- } \\
\text { sis (FEME) }\end{array}$ & Yes [44] & $\begin{array}{l}\text { Tubulo-vesicular, } \\
100 \text { nm- } \mu \text { m length }\end{array}$ & $\beta 1 \mathrm{AR}[44,45]$ & Yes [44] & Yes [44] & $\begin{array}{l}\text { BSC 1, HEK293 cells } \\
\text { [44] }\end{array}$ \\
\hline $\begin{array}{l}\text { Activity-dependent } \\
\text { bulk endocytosis } \\
\text { (ADBE) }\end{array}$ & Yes $[46,47]$ & $150 \mathrm{~nm}$ & VAMP4 [48] & Yes [49] & Yes [50] & $\begin{array}{l}\text { Murine cerebellar } \\
\text { granule cells [51] }\end{array}$ \\
\hline $\begin{array}{l}\text { Ultrafast endocytosis } \\
\text { (UFE) }\end{array}$ & Yes [52] & $60-80$ nm $[52,53]$ & Unclear & Yes [54] & Yes [52] & $\begin{array}{l}\text { Nematode neurons } \\
\text { [55] }\end{array}$ \\
\hline $\begin{array}{l}\text { Massive endocytosis } \\
\text { (MEND) }\end{array}$ & No $[56,57]$ & $<100 \mathrm{~nm}[57]$ & $\begin{array}{l}\text { Phospholemman, } \\
\text { polypalmitoylated } \\
\text { proteins [58] }\end{array}$ & Yes [59] & No $[56,57]$ & BHK, HEK293 cells [57] \\
\hline Macropinocytosis & Yes $[60,61]$ & $200 \mathrm{~nm}-20 \mu \mathrm{m}$ & Non-selective & Yes $[62,63]$ & Unclear & $\begin{array}{l}\text { Murine sarcoma cells } \\
\text { [64] }\end{array}$ \\
\hline
\end{tabular}


caves, constitute small, flask-shaped membrane bulbs $50-100 \mathrm{~nm}$ in diameter and are enriched in vascular endothelial cells, epithelial cells, adipocytes, and fibroblasts [72, 73]. Trafficking of caveolar endosomes and delivery of their lumenal contents to organelles is poorly understood, in part because of overlap between cargoes sorted into the caveolae-dependent pathway and the CLIC-GEEC pathway [19].

Many proteins that are lipid-anchored to the outer leaflet of the plasma membrane, such as GPI-anchored aminopeptidases (GPI-APs), are endocytosed in uncoated, clathrin-independent carriers (CLICs) that are derived from the plasma membrane and enriched in large tubulovesicular structures called GPI-AP Enriched Early Endosomal Compartments (GEECs) [20, 21]. Endocytosis via the CLIC-GEEC pathway accounts for a significant proportion of internalized membrane and fluid-phase contents and in this respect resembles macropinocytosis, another form of CIE. Unlike macropinocytosis, however, CLIC-GEEC endocytosis is insensitive to amiloride inhibition [74].

The CLIC/GEEC pathway is initiated by membrane recruitment of GBF1, a guanine nucleotide exchange factor (GEF) for the GTP-binding protein ADP-ribosylation factor 1 (Arf1) [75]. Consequent to activation of Arf1 by GBF1, the Rho GTPase activating protein (GAP) ARHGAP10/21 is locally recruited and promotes the GTP cycling of Cdc42 [75]. Cdc42 dynamics at the membrane, in turn, regulate recruitment of downstream effectors that direct actin polymerization and promote the formation of CLICs. Enrichment of CLICs in GEECs is regulated by recruitment of GTPase regulator associated with focal adhesion kinase1 (GRAF1), a BAR-domain-containing protein that also negatively regulates $\mathrm{Cdc} 42$ via its Rho-GAP domain [18]. While the CLIC/GEEC pathway does not require Dynamin-1 or -2 for endocytosis of its cargoes, dynamin does associate with GEECs post-internalization [20].

Flotillin-dependent endocytosis is a form of CIE requiring flotillin (reggie) proteins, genes for which are highly conserved among metazoans [76]. Flotillins are characterized by N-terminal hydrophobic stomatin/prohibitin/flotillin/HflK/C (SPFH) domains shown to regulate membrane targeting in adipocytes and $\mathrm{C}$-terminal flotillin domains necessary for oligomerization [77-79]. Flotillins associate with lipid rafts and generate membrane invaginations through mechansims that remain largely undefined [80]. The role of dynamin in flotillindependent endocytosis is also unclear, as is the mechanism governing cargo specificity. For these reasons, some have argued that flotillins may not characterize a distinct endocytic pathway at all but instead function as adaptors in other forms of CIE [81].
Many cytokine receptors are internalized via a cholesterol-sensitive pathway termed RhoA-dependent IL-2R $\beta$ endocytosis for the receptor that historically first defined it. This form of CIE, which is initiated at the base of membrane protrusions, requires activation of the small GTPases RhoA and Rac1 as well as signaling through p21-activated kinases (Paks) [25, 26]. Two rounds of actin polymerization drive vesicular budding, maturation, and scission to form vesicles $50-100 \mathrm{~nm}$ in diameter [25, 26]. Dynamin has been shown to coordinate progressive recruitment of the actin effectors WAVE and N-WASP in IL-2R $\beta$ endocytosis [25].

A variety of cell surface proteins, including those regulating nutrient and cholesterol homeostasis, are internalized in a manner requiring the small GTPase ADP-ribosylation factor 6 (Arf6) [82]. Arf6 GTP-loading in tubular endosomes promotes their recycling to the plasma membrane as well as the generation of actin-rich protrusions [31]. Mechanistically, Arf6-GTP activates phosphatidylinositol-4-phosphate 5-kinase, which in turn recruits additional signaling molecules to sites of active cytoskeletal arrangement to promote cargo internalization [83]. Intracellularly, Arf6-GDP associates with tubular early endosomes, then Rab5-positive sorting endosomes [84]. Subsequent trafficking events are regulated by the CME adaptor protein AP-2 [85]. Thus, Arf6 has been implicated in both CIE and dynamin-2-dependent CME [86].

Phagocytosis a form of CIE that involves the specific recognition and uptake of particles $>500 \mathrm{~nm}$ into membrane-derived vesicles known as phagosomes [87]. Phagocytosis is essential for development and tissue homeostastis, as well as a first line of defense against pathogens by innate immune cells [87]. Phagocytosis in these cells enables presentation of antigen to lymphocytes and activation of adaptive immune responses. Phagocytic target ligands are recognized by surface receptors that can be broadly classified as opsonic and non-opsonic. Opsonic receptors recognize foreign particles indirectly by binding host-derived opsonins [87]. Non-opsonic receptors include those that recognize pathogen-associated molecular patterns, as well as those that recognize apoptotic and necrotic cells [87]. Ligand binding initiates intracellular signaling cascades that activate the nonreceptor protein tyrosine kinase Syk, generate phosphoinositide second messengers, and recruit activated Rho GTPases [87-89]. GTP-loaded Rho GTPases coordinate actin polymerization in phagocytic cups to engulf and internalize the particle [87].

Pinocytosis refers to non-specific endocytosis of contents dissolved in the fluid phase into vesicles of any size [90]. Micropinocytosis, the ingestion of fluid-phase contents into vesicles $<100 \mathrm{~nm}$ in diameter, is today and 
archaic term as it is now known to encompass a number of distinct endocytic pathways described elsewhere in this review. Macropinocytosis, however, refers to a distinct, evolutionarily-ancient, bulk form of endocytosis that is actin-mediated and leads to the generation of vesicles (macropinosomes) ranging in size from $200 \mathrm{~nm}$ to $5 \mu \mathrm{m}$ in diameter [91]. All forms of fluid-phase endocytosis regulate cellular absorption of water, nutrients, and ions from the extracellular environment, though macropinocytosis regulates these processes at high throughput scale.

Macropinosomes are generated from large membrane ruffles and lamellapodial protrusions that either meet other protrusions at their distal margins or collapse back into the plasma membrane. In some respects macropinocytosis resembles phagocytosis, but unlike phagocytosis it is uniquely inhibited by amilorides, which block plasma membrane $\mathrm{Na}^{+} / \mathrm{H}^{+}$exchangers $[60,92]$. Macropinocytosis has been adapted for roles in diverse cellular processes including directed cell migration, feeding, and immune surveillance in antigen-presenting cells [91, 93, 94]. It is also exploited by some cancers to enable metabolic adaption and survival under nutrient-depleted conditions [95-97]. Growth factor-stimulated macropinocytosis has been shown to rely on sustained signaling through a Receptor Tyrosine Kinase (RTK)/PI3K signaling axis but RTK-independent, constitutive macropinocytosis has also been demonstrated [98].

Fast Endophilin Mediated Endocytosis (FEME) is a form of CIE regulated by the BAR-domain-containing protein endophilin, which has five paralogs in humans (A1, A2, A3, B1, and B2) [45]. FEME is a non-constitutive mode of endocytosis that occurs in response to activation of G-protein-coupled receptors (GPCRs) and cytokine receptors by their ligands. Activated receptors are sorted into pre-existing membrane clusters of endophilin that are rapidly $(\sim 5-10 \mathrm{~s})$ internalized in tubulo-vesicular carriers $100 \mathrm{~nm}$ to microns in length that most closely resemble CLICs [44]. This form of CIE is dynamindependent, and, like many other forms of endocytosis, is regulated by phosphoinositide and kinase signaling [45]. In addition to its essential role in FEME, endophilin has been implicated in both IL-2R $\beta$ endocytosis and CME; knock-down of endophilin has been shown to decrease the rate of IL-2R $\beta$ internalization and to be required for the uncoating of CCVs in CME $[44,99]$.

Two high-capacity modes of CIE of special importance in neurons are Activity-Dependent Bulk Endocytosis (ADBE) and Ultrafast Endocytosis (UFE). Both are dynamin-dependent forms of CIE that, like FEME, are characterized by their rapidity. ADBE has been shown to internalize large patches of membrane and aid in the retrieval of synaptic vesicles (SVs) at central nerve terminals in response to high neuronal activity [46]. Mechanistically, ADBE requires interaction between dynamin and syndapin 1 to associate with N-WASP, an effector of actin nucleation and polymerization [100]. UFE occurs in response to more mild stimulation, $50-100 \mathrm{~ms}$ after propagation of an action potential, and enables the recycling of synaptic vesicle components, such as SNAREs and synucleins [52, 101]. Like FEME, endophilin has been implicated in regulation of UFE [102].

Lastly, Massive ENDocytosis (MEND) is a dynaminindependent form of CIE that does not require actin remodeling [57]. As the name suggests, MEND enables the internalization of very large membrane patches in response to metabolic stress, $\mathrm{Ca}^{2+}$ signaling, and other stimuli, in a manner driven by membrane phase separation $[56,103]$. In this process, membranes of heterogenous lipid composition can partition into different nanodomains with intrinsic curvature, which facilitates endocytosis without actin remodeling.

\section{T cell endocytosis}

CME and CIE facilitate a range of $\mathrm{T}$ cell specific functions, as summarized in Table 2. Chief among these are the regulation of plasma membrane immune receptors and signaling, including internalization and recycling of $\mathrm{T}$ cell antigen receptors (TCRs). Endocytic mechanisms are also critical for stable conjugate formation between $\mathrm{T}$ cells and APCs. They also enable trogocytic exchange of receptor complexes between individual $\mathrm{T}$ cells, as well as between T cells and APC. Lastly, TCR-stimulated uptake of key amino acids by macropinocytosis plays a critical role in promoting $\mathrm{T}$ cell anabolism and growth by sustaining activation of the mechanistic target of rapamycin complex 1 (mTORC1).

Plasma membrane immune receptor and ligand regulation Endocytosis of plasma membrane receptors and the trafficking, recycling, and targeted degradation of receptor components are integral to many cellular responses, including those of $\mathrm{T}$ cells. Both CME and CIE pathways have been shown to regulate plasma membrane immune receptors in both TCR $\alpha \beta$ and $\gamma \delta$ T cells.

The immune checkpoint protein CTLA-4, which negatively regulates TCR $\alpha \beta$ T cell activation by out-competing CD28 and trans-endocytosing its ligands CD80 and CD86, is constitutively internalized by $\operatorname{CME}[104,105]$. This occurs in a ligand- and dynamin-independent manner and results in both recycling to the cell surface and trafficking to lysosomes for degradation. Constitutive, ligand-independent internalization continues even as CTLA-4 surface expression is upregulated during $\mathrm{T}$ cell activation. 
Table 2 Forms of endocytosis described in T lymphocytes

\begin{tabular}{|c|c|c|}
\hline & Described in T cells & Function in T cells \\
\hline Clathrin-dependent endocytosis & Yes & $\begin{array}{l}\text { Plasma membrane receptor regulation }[104,105], \text { TCR a } \beta \\
\text { endocytosis }[106-108]\end{array}$ \\
\hline CLIC/GEEC pathway endocytosis & Yes & TCR endocytosis [109] \\
\hline Flotillin-dependent endocytosis & Yes & TCR a $\beta$ recycling [110], conjugate formation with APCs [1 10] \\
\hline IL-2Rß pathway endocytosis & Yes & IL-2Rß complex endocytosis $[25,111]$ \\
\hline Arf6-dependent endocytosis & Yes & Conjugate formation with APCs [112] \\
\hline Phagocytosis & Yes & $\begin{array}{l}\text { Host defense/immune surveillance ( } \gamma \delta \text { T cells) }[113,114] \text {, } \\
\text { trogocytosis (TCR aßT cells) }[115]\end{array}$ \\
\hline Caveolae-dependent endocytosis & No & N/A \\
\hline Macropinocytosis & Yes & mTORC1 activation and growth [98] \\
\hline Fast endophilin-mediated endocytosis (FEME) & Yes & IL-2Rß complex endocytosis [44] \\
\hline Activity-dependent bulk endocytosis (ADBE) & No & N/A \\
\hline Ultrafast endocytosis (UFE) & No & N/A \\
\hline Massive endocytosis (MEND) & No & N/A \\
\hline
\end{tabular}

In thymus-dependent humoral immune responses, transient expression of the transmembrane glycoprotein CD40-L on CD4 ${ }^{+}$TCR $\alpha \beta$ T cells provides an essential, contact-dependent, co-stimulatory signal to cognate $\mathrm{B}$ cells. $\mathrm{CD}^{+} \mathrm{T}$ cell CD40-L binding to CD40 on B cells initiates an intracellular signaling cascade that promotes the generation of class-switched, high-affinity antibodies, as well as the establishment of B cell memory and differentiation into long-lived plasma cells. In addition to the well-established transfer of CD40-L from Tfh cells to cognate B cells via an unknown exocytic mechanism, down-modulation and lysosomal degradation of plasma membrane CD40-L has also been shown to occur in $\mathrm{T}$ cell tumor lines [116]. Endocytosis of CD40-L in these cells requires actin polymerization, though its dependence on clathrin and dynamin have not been established.

By contrast, the rapid internalization of IL-2R complexes from the surface of activated TCR in $\alpha \beta$ T cells has been shown to occur by CIE [111]. IL-2R $\beta$ endocytosis was first demonstrated to be clathrin-independent in studies employing dominant-negative mutants of the essential clathrin coated pit and vesicle component Eps15 [111]. Endocytosis of IL-2R $\beta$ complexes in these experiments occurred normally in the absence of CME as measured by transferrin uptake. In addition to dynamin, IL-2R $\beta$ internalization requires the cytoplasmic tail of the component $\gamma_{c}$ chain, as well as both the catalytic activity and p85 regulatory subunit of PI3K $[117,118]$. The constituent subunits of the receptor partition into different compartments soon after internalization, with the comparatively stable $\alpha$ chain confined to transferrin-positive recycling endosomes (suggesting partial utilization of the CME pathway) whereas the $\beta$ and $\gamma_{c}$ chains are sorted into late endosomes and thereafter targeted to lysosomes for degradation [119]. The proteasome has also been shown to be important, not for the initial phase of IL-2R $\beta$ endocytosis but for its continuance and lysosomal targeting of the $\beta$ and $\gamma_{c}$ subunits [120]. The co-localization of endophilin with IL-2R $\beta$ vesicular cargoes in the human $\mathrm{T}$ cell line Kit255, as well as the specific diminution of IL-2R $\beta$ internalization in cells depleted of endophilin, implicate FEME as a mechanism of IL-2R $\beta$ endocytosis [44]. Whether these represent two distinct endocytic pathways or simply utilize shared machinery remains to be clarified.

WC1 proteins, transmembrane glycoproteins of the scavenger receptor cysteine-rich family, are co-receptors of the TCR in $\gamma \delta$ T cells. They are thought to function as bacterial pattern recognition receptors that regulate cell activation by co-ligation with the $\gamma \delta$ TCR [121]. WC1 is endocytically down-regulated in response to non-specific stimulation by phorbol 12-myristate 13-acetate (PMA) [122]. It has been shown in Jurkat $\mathrm{T}$ cells that a dileucine motif in the cytoplasmic domain of WC1 regulates co-receptor endocytosis induced by PMA [121]. In this system, sustained co-ligation of the TCR and a transmembrane fusion protein consisting of the CD4 extracellular domain joined to the WC1 transmembrane and cytoplasmic domains enhanced $\mathrm{T}$ cell activation, as measured by elevated IL-2 production [121]. Like the CD3 $\gamma, \mathrm{CD} 3 \delta$, and CD4 intracellular domains, the proximal cytoplasmic tail of WC1 contains a [DE]XXXL[LIM] dileucine motif known to bind to the adaptor protein (AP-2) components of CCPs and CCVs [121]. The presence of this motif on WC1 family proteins suggests that endocytosis of the WC1 coreceptor in $\gamma \delta$ T cells is regulated by CME. 


\section{Endocytosis of the TCR in $\alpha \beta$ T cells}

In the absence of stimulation, non-engaged TCRs are constitutively internalized by dynamin-dependent CME and recycled back to the cell surface [106]. Endocytosis of engaged TCRs, on the other hand, occurs by both CME and CIE [110]. Mechanosensory cues appear to play a role in dictating which mode predominates: TCR triggering with soluble anti-CD3 antibodies promotes internalization by $\mathrm{CME}$, whereas triggering by anti-CD3 immobilized on plastic promotes CIE of engaged TCRs [106].

The clathrin-dependent pathway requires dynamin and is similarly regulated by a CD3y dileucine endocytosis motif. Endocytosis and signaling from engaged TCRs is tightly coupled, as it is for other signaling components of TCR microclusters, such as LAT, ZAP-70, and SLP-76. It has been shown in $\mathrm{CD}^{+}$and $\mathrm{CD}^{+}$human $\mathrm{T}$ cell lines that the Src family kinase Lck, a key component of the $\mathrm{T}$ cell signalosome, promotes CME of the TCR upon receptor engagement and lysosomal degradation [107, 123]. It does so by inducible phosphorylation of tyrosine residues on the clathrin heavy chain $(\mathrm{CHC})$ which interact with the clathrin light chain to regulate cage assembly [107]. Basal Lck phosphorylation of the $\mathrm{CHC}$ also plays a role in constitutive endocytosis of the TCR, as unstimulated cells deficient in Lck exhibit no TCR internalization [107]. Another Src family kinase that regulates proximal TCR signaling, Fyn, also promotes CME of the TCR, since human T cell lines deficient in CD45, and therefore unable to activate Lck or Fyn, exhibit less internalization than those deficient in Lck alone [123, 124].

An adaptor protein critical for the early-stage assembly of CCPs, the FCH domain only 1 (FCHO1) protein, also plays a critical role in CME of engaged TCRs. First identified by whole exome sequencing in human patients with combined immunodeficiency, loss-of-function mutations in FCHO1 profoundly impair ligand-induced TCR clustering and endocytosis [108, 125]. FCHO1 deletion in Jurkat $\mathrm{T}$ cells recapitulates this phenotype and can be rescued by expression of wild-type FCHO1 [108].

Another adaptor critical for CME of engaged TCRs is the cytoplasmic protein intersectin 2 , which has been shown to promote the translocation of $\mathrm{Cdc} 42$ and its effector Wiskott-Aldrich Syndrome protein (WASP) to CCVs in Jurkat cells [126]. Intersectin 2 also activates Cdc42 by its Dbl homology (DH)/RhoGEF domain. Overexpression of intersectin 2 in Jurkats substantially increases TCR internalization whereas expression of an intersectin $2 \Delta \mathrm{DH}$ construct markedly reduced it [126]. In this way, intersectin 2 may link the machinery of actin polymerization with that of CME in T cells.

Sustained TCR signaling is required for full cell activation and this depends critically on the delivery of signaling-competent, TCR-laden recycling endosomes to the immunological synapse (IS) [127]. This mechanism compensates for the activation-induced downmodulation of engaged receptors, which is required for serial triggering of receptors and desensitization of stimulated cells. It has also recently been shown that activated TCR-CD3 $\zeta$ complexes internalized by $\mathrm{CME}$ continue to signal from endosomes positive for insulin responsive aminopeptidase (IRAP) and Syntaxin 6, and that this activity is required for efficient anti-tumor $\mathrm{T}$ cell responses [128].

Interestingly, selective triggering of the TCR complex has been shown to also cause the concomitant downregulation of non-engaged TCRs in a manner regulated by protein kinase $\mathrm{C} \theta$ (PKC $\theta$ ) and the CME adaptor AP-2 [129]. Bystander TCR downmodulation that occurs concomitantly with TCR ligation, however, uniquely requires protein tyrosine kinase (PTK) activity [106].

The clathrin-independent pathway of TCR endocytosis uniquely utilizes the Rras subfamily GTPase TC21. TC21 promotes internalization by a mechanism reliant on the small GTPase RhoG, previously implicated in both phagocytosis and caveolar endocytosis [115, 130,131].

The CLIC-GEEC pathway of CIE has also been implicated in TCR endocytosis in activated Jurkat T cells. In this system, CD3 triggering resulted in TCR $\zeta$ accumulation in tubular invaginations of the plasma membrane that are shaped by actin polymerization downstream of the Rho GTPase Cdc42 [109]. The BAR domain-containing protein GRAF1 is recruited to these structures, where it promotes Cdc42 GTP hydrolysis via its GAP domain. These tubular invaginations mature into endocytic vesicles that show co-localization of the internalized TCR with cholera toxin $\mathrm{B}$ and $\mathrm{CD} 44$, established cargoes of the CLIC-GEEC pathway [109].

A number of proteins associated with CIE pathways appear to regulate TCR endocytosis through their effects on endocytic trafficking. The actin-binding protein HIP55 is recruited to the IS in activated Jurkat cells and associates with early endosomes and dynamin [132]. In these cells, HIP-55 expression promotes basal and liganddependent TCR down-modulation, most likely by interfering with receptor recycling [132].

Members of the EPS15 Homology Domain-containing (EHD) family of endocytic traffic regulators are expressed in murine $\mathrm{CD}^{+} \mathrm{T}$ cells and have also been implicated in the regulation of cell surface receptors. $\mathrm{CD} 4^{+} \mathrm{T}$ cells from conditional knockout EHD1/3/4 mice exhibit reduced proliferation and IL-2 secretion in response to antigen stimulation in vitro, as well as impaired TCR recycling, and enhanced lysosomal degradation of TCR components [133]. Support for a role in these processes comes from the association of EHD proteins with Rab 
effector proteins, which regulate endocytic trafficking [133].

Membrane-organizing flotillin proteins incorporate into pre-assembled signaling platforms that asymmetrically localize to one pole in hematopoietic cells, including $T$ cells [134]. Immediately upon internalization, engaged TCRs are incorporated into a stable, mobile endocytic network defined by flotillins [110]. Consistent with the idea that flotillins may function as adaptors for other endocytic pathways, as opposed to demarcating a distinct, bona fide form of endocytosis, they are not required for internalization of engaged TCRs. Like EHD proteins, flotillins may regulate TCR surface expression by promoting endocytic recycling. Flotillins are required for the trafficking of downmodulated TCRs to Rab5-positive sorting endosomes, from Rab5- to Rab11a-positive recycling endosomes, and their recycling to the IS [110, $135]$.

\section{Arf6-mediated endocytosis and flotillins in APC conjugate formation}

The formation of stable conjugates between $\mathrm{T}$ cells and APCs requires Arf6, Rab22, and flotillins [112]. Expression of a constitutively-active form of Arf6 in Jurkat $\mathrm{T}$ cells inhibits endocytosis of MHC class I, and causes other cargoes important for IS formation, such as CD4 and LFA-1, to accumulate in enlarged, Arf6-positive vacuoles [112]. Consequently, conjugate formation with APCs is impaired. In addition to Arf6, the GTPase Rab22 (a.k.a. Rab22a) is also required to form stable Jurkat-Raji (B) cell conjugates as expression of a dominant-negative form of it (Rab22S19N) is sufficient to impair their formation [112]. Additionally, Jurkat T cells deficient in flotillin1/2 show are unable to form stable conjugates with Raji cells, demonstrating a requirement for flotillin proteins in this process as well [110].

\section{Phagocytosis in TCR $\gamma \delta$ T cells}

Previously thought to be limited to cells of the myeloid lineage, it is now known that human peripheral $\gamma \delta \mathrm{T}$ cells not only have phagocytic capabilities but can act as "professional" phagocytes in that they are capable of presenting processed antigen on MHC class II to TCR $\alpha \beta$ T cells $[113,114]$. Indeed, TCR $\gamma \delta$ T cells can ingest entire bacteria, such as L. monocytogenes and E. coli $[113,114]$. Presumably the maturation of phagosomes in these cells resembles and depends on the same machinery as other professional phagocytes (e.g., Rab5/7, RILP, etc.) though very little is currently known about this.

\section{Trogocytosis}

Trogocytosis refers to the exchange of intact membrane patches between cells. While not, strictly-speaking, a form of endocytosis, in vitro studies have suggested a mechanism with qualitative similarity to that of phagocytosis. An increasing body of evidence suggests not only that $\mathrm{T}$ cell trogocytosis is a ubiquitous phenomenon in vivo, but that it constitutes an important mechanism of intercellular communication and immune modulation [136-139]. Trogocytosis has even been shown to convey novel functional capabilities from one cell type to another through the acquisition of membrane-associated molecules [136, 140].

In Jurkat $\mathrm{T}$ cells, TCR-mediated trogocytic uptake of peptide:MHC complexes from antigen-presenting cells requires TC21 (Rras2) and the phagocytosis-associated GTPase RhoG $[115,141]$. In CD4 ${ }^{+}$TCR $\alpha \beta$ T cells, trogocytic exchange of peptide:MHC complexes has been shown to influence $\mathrm{T}$ effector cell polarization [138]. When stimulated by murine fibroblasts and peptidepulsed bone marrow-derived dendritic cells expressing peptide:MHC complexes, trogocytosis-positive CD4 ${ }^{+}$ $\mathrm{T}$ cells activated the transcription factor GATA-3 and produced IL-4 both in vitro and in vivo, consistent with Th2 polarization [138]. The mechanism responsible for this polarization remains to be elucidated, though it may relate to the strength and duration of TCR stimulation.

Even more remarkably, virus-specific $\mathrm{CD}^{+}$cytotoxic $\mathrm{T}$ lymphocytes (CTLs) are capable of transferring their TCRs via trogocytosis to recipient CTLs of different clonotypic specificity [142]. Acquisition of donor TCRs confers the ability to recognize additional antigen and enables expansion of virus-specific clones independent of proliferation [142]. On the other hand, the detrimental potential of trogocytosis-mediated $\mathrm{T}$ cell plasticity is demonstrated by a recent study by Haimeh et al. examining chimeric antigen receptor (CAR) T cell responses in a mouse leukemia model. In this work, trogocytic acquisition of target antigen by CAR $\mathrm{T}$ cells not only reduced target density on tumor cells but promoted "fratricidal" (mutual) CAR T cell killing and exhaustion [143].

\section{Macropinocytosis}

Macropinocytosis has been described in both murine and human primary TCR $\alpha \beta$ T cells. It is a constitutive activity in naïve $\mathrm{T}$ cells that is upregulated severalfold in response to stimulation and activation [98]. One established function of macropinocytosis in $\mathrm{T}$ cells is to internalize and deliver free amino acids (as opposed to protein) obtained from the extracellular space to the lysosome [98]. Intralumenal amino acids signal, most likely through a membrane transceptor, to promote the activation of the mechanistic target of rapamycin complex 1 (mTORC1), a central regulator of anabolism and cellular growth [98]. In this way, macropinocytosis promotes 
nutrient acquisition and growth signaling in $\mathrm{T}$ cells preparing to undergo clonal expansion (Fig. 1).

It is interesting to speculate on the reasons why TCRstimulated macropinocytosis is required for optimal activation of naïve $\mathrm{CD} 4^{+}$and $\mathrm{CD} 8^{+} \mathrm{T}$ cells. After all, most if not all of the forms of endocytosis previously described are sufficient to transport amino acids and a wide variety of amino acid transporters are expressed in these cells. One possibility is that transport through other endocytic pathways does not license lysosomal delivery of internalized cargoes. Some pathways clearly are sufficient for this purpose: the IL-2-IL2R complex has been shown to deliver IL-2 to primary $\mathrm{T}$ cell lysosomes, albeit with a required stopover at the proteasome beforehand [120].

A more likely explanation is that while naïve $\mathrm{T}$ cells express abundant plasma membrane amino acid transporters, their flux capacity is insufficient to meet the demand of $\mathrm{T}$ cell activation. Activation requires dramatic increases in amino acid and glucose uptake to enable previously metabolically quiescent cells to upregulate aerobic glycolysis and glutaminolysis. Consequently, TCR signaling and co-stimulation substantially increases expression and plasma membrane localization of GLUT1 and amino acid transporters such as LAT1, SNAT-1, and SNAT-2 [144]. It's possible that lysosomal import of cytoplasmic amino acids requires an adaptor that is not abundantly expressed in naïve or nascently-activated $\mathrm{T}$ cells. Such is the case for the adaptor LAPTM4b, which recruits the LAT1 transporter to the lysosome and is required for mTORC1 activation in HeLa cells [145].

Another possibility is that, bulk acquisition of amino acids by macropinocytosis may more rapidly or efficiently activate lysosomal mTORC1 complexes than the transcription, translation, and membrane-targetting of activation-induced transporters will permit. The nearly indetectable levels of LAT1 protein in naïve human T cells support this hypothesis [146].

A last (and not mutually exclusive) possibility is that maximal mTORC1 activation in these cells requires not only an intralysosomal amino acid sufficiency signal but also a second signal conveyed by cytoplasmic amino acid sensors like Sestrin2 and CASTOR1. In this way, mTORC1 may function like an AND gate, sensitive to both intracellular and extracellular amino acid signal inputs, where a concentration gradient exists between lysosomal and cytoplasmic amino acid pools.

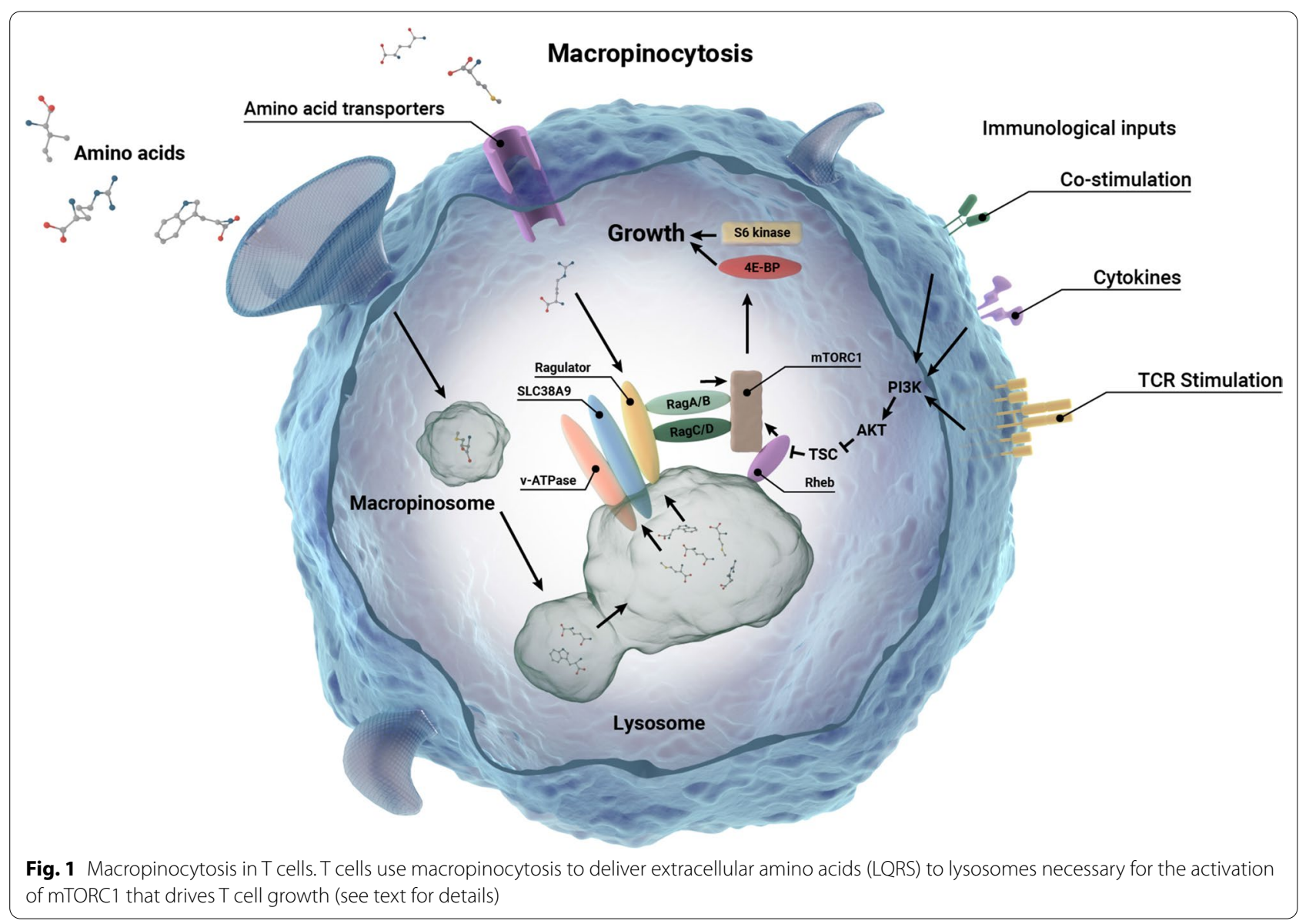




\section{Conclusions}

The term endocytosis encompasses a range of diverse cellular mechanisms for regulating membrane composition and internalizing contents from the extracellular space. While CME has been shown to be the principal housekeeping mode of endocytosis in resting cells, multiple, overlapping modes of CIE have more recently been described in most eurkaryotic cell types. In T cells both CME and CIE are employed to facilitate cell-specific functions, including regulation of $\mathrm{T}$ cell receptor internalization and signaling, interaction with APCs, effector cell polarization, and nutrient acquisition. With the exception of caveolae-dependent endocytosis and several high capacity modes of endocytosis that appear to be specific to neurons, flux through CIE pathways regulates and enables a range of critical $\mathrm{T}$ cell functions.

\begin{abstract}
Abbreviations
ADBE: Activity-dependent bulk endocytosis; APC: Antigen-presenting cell; Arf1/6: ADP-ribosylation factor 1/6; CASTOR1: Cytosolic arginine sensor for mTORC1 subunit 1; CCP: Clathrin coated pit; CCV: Clathrin coated vesicle; CIE: Clathrin-independent endocytosis; CLIC/GEEC: Clathrin-independent carrier/ GPI-AP-enriched early endosomal compartment; CME: Clathrin-mediated endocytosis; CTL: Cytotoxic T lymphocyte; EHD: EPS15 Homology Domaincontaining; FCHO1: FCH domain only 1; FEME: Fast endophilin-mediated endocytosis; GRAF1: GTPase regulator associated with focal adhesion kinase1; LAT1: Large amino acid transporter 1; LFA-1: Lymphocyte function-associated antigen-1; MEND: Massive enocytosis; MHC: Major histocompatibility complex; mTORC1: Mechanistic target of rapamcyin; Paks: P21-activated kinases; PKC $\theta$ : Protein kinase C $\theta$; PMA: Phorbol 12-myristate 13-acetate; RILP: Rab-interacting lysosomal protein; RTK: Receptor tyrosine kinase; SNAT-1/2: Sodium-coupled neutral amino acid transporter-1/2; SVs: Synaptic vesicles; TCR: T cell receptor; Tfh: T follicular helper; UFE: Ultrafast endocytosis; WASP: Wiskott-Aldrich syndrome protein; WAVE: WASP-family verprolin homologous protein.
\end{abstract}

\section{Acknowledgements}

Professor Joel Swanson is thanked for his review of the manuscript and helpful suggestions prior to submission.

\section{Authors' contributions}

J.C.C. wrote the manuscript with assistance from P.D.K. All authors read and approved the final manuscript.

\section{Funding}

J.C.C. was supported by NIH Al T32007413 Research Training in Experimental Immunology Training Grant and a Rackham Graduate School Fellowship.

\section{Availability of data and materials}

Not applicable.

\section{Declarations}

Ethics approval and consent to participate

Not applicable.

\section{Consent for publication}

Not applicable.

\section{Competing interests}

The author declare they have no competing interests.
Received: 22 March 2021 Accepted: 17 July 2021

Published online: 09 September 2021

\section{References}

1. de Duve C. The origin of eukaryotes: a reappraisal. Nat Rev Genet. 2007:8:395-403.

2. Mooren OL, Galletta BJ, Cooper JA. Roles for actin assembly in endocytosis. Annu Rev Biochem. 2012;81:661-86.

3. McMahon HT, Boucrot E. Molecular mechanism and physiological functions of clathrin-mediated endocytosis. Nat Rev Mol Cell Bio. 2011;12:517-33.

4. Mayle KM, Le AM, Kamei DT. The intracellular trafficking pathway of transferrin. Biochim Biophys Acta Bba Gen Subj. 2012;1820:264-81.

5. Subtil A, et al. Acute cholesterol depletion inhibits clathrin-coated pit budding. Proc National Acad Sci. 1999;96:6775-80.

6. van der Bliek A, et al. Mutations in human dynamin block an intermediate stage in coated vesicle formation. J Cell Biol. 1993;122:553-63.

7. Damke H, Baba T, Warnock DE, Schmid SL. Induction of mutant dynamin specifically blocks endocytic coated vesicle formation. J Cell Biology. 1994;127:915-34.

8. Roth TF, Porter KR. Yolk protein uptake in the oocyte of the mosquito Aedes aegypti L. J Cell Biol. 1964;20:313-32.

9. Echarri A, Pozo MAD. Caveolae-mechanosensitive membrane invaginations linked to actin filaments. J Cell Sci. 2015;128:2747-58.

10. Echarri $A$, et al. Caveolar domain organization and trafficking is regulated by Abl kinases and mDia1. J Cell Sci. 2012;125:3097-113.

11. Stoeber M, et al. Oligomers of the ATPase EHD2 confine caveolae to the plasma membrane through association with actin. Embo J. 2012;31:2350-64.

12. Pelkmans L, Helenius A. Endocytosis via caveolae. Traffic. 2002;3:311-20.

13. Nabi IR, Le PU. Caveolae/raft-dependent endocytosis. J Cell Biol. 2003;161:673-7.

14. Henley JR, Krueger EWA, Oswald BJ, McNiven MA. Dynamin-mediated Internalization of Caveolae. J Cell Biol. 1998;141:85-99.

15. Yamada E. The fine structure of the gall bladder epithelium of the mouse. J Biophys Biochem Cytol. 1955;1:445-58.

16. Chadda R, et al. Cholesterol-sensitive Cdc42 activation regulates actin polymerization for endocytosis via the GEEC pathway. Traffic. 2007;8:702-17.

17. Sathe M, et al. Small GTPases and BAR domain proteins regulate branched actin polymerisation for clathrin and dynamin-independent endocytosis. Nat Commun. 2018;9:1835.

18. Lundmark $R$, et al. The GTPase-activating protein GRAF1 regulates the CLIC/GEEC endocytic pathway. Curr Biol. 2008;18:1802-8.

19. Chaudhary N, et al. Endocytic crosstalk: cavins, caveolins, and caveolae regulate clathrin-independent endocytosis. Plos Biol. 2014;12:e1001832.

20. Kirkham $M$, et al. Ultrastructural identification of uncoated caveolinindependent early endocytic vehicles. J Cell Biol. 2005;168:465-76.

21. Sabharanjak S, Sharma P, Parton RG, Mayor S. GPI-anchored proteins are delivered to recycling endosomes via a distinct cdc42-regulated, clathrin-independent pinocytic pathway. Dev Cell. 2002;2:411-23.

22. Langhorst MF, Solis GP, Hannbeck S, Plattner H, Stuermer CAO. Linking membrane microdomains to the cytoskeleton: regulation of the lateral mobility of reggie-1/flotillin-2 by interaction with actin. Febs Lett. 2007;581:4697-703.

23. Ge $\mathrm{L}$, et al. Flotillins play an essential role in Niemann-Pick C1-like 1-mediated cholesterol uptake. Proc Natl Acad Sci. 2011;108:551-6.

24. Glebov OO, Bright NA, Nichols BJ. Flotillin-1 defines a clathrinindependent endocytic pathway in mammalian cells. Nat Cell Biol. 2006;8:46-54

25. Basquin C, et al. Membrane protrusion powers clathrin-independent endocytosis of interleukin-2 receptor. Embo J. 2015;34:2147-61.

26. Grassart A, Dujeancourt A, Lazarow PB, Dautry-Varsat A, Sauvonnet N. Clathrin-independent endocytosis used by the IL-2 receptor is regulated by Rac1, Pak1 and Pak2. Embo Rep. 2008;9:356-62.

27. Matkó J, et al. GPI-microdomains (membrane rafts) and signaling of the multi-chain interleukin-2 receptor in human lymphoma/leukemia T cell lines. Eur J Biochem. 2002;269:1199-208. 
28. Vereb G, et al. Cholesterol-dependent clustering of IL-2Ra and its colocalization with HLA and CD48 on T lymphoma cells suggest their functional association with lipid rafts. Proc Natl Acad Sci. 2000;97:6013-8.

29. Sauvonnet N, Dujeancourt A, Dautry-Varsat A. Cortactin and dynamin are required for the clathrin-independent endocytosis of $\gamma c$ cytokine receptor. J Cell Biol. 2005;168:155-63.

30. Hémar A, Lieb M, Subtil A, Disanto JP, Dautry-Varsat A. Endocytosis of the $\beta$ chain of interleukin-2 receptor requires neither interleukin- 2 nor the $\gamma$ chain. Eur J Immunol. 1994;24:1951-5.

31. Radhakrishna H, Donaldson JG. ADP-ribosylation factor 6 regulates a novel plasma membrane recycling pathway. J Cell Biol. 1997;139:49-61.

32. Naslavsky N, Weigert R, Donaldson JG. Characterization of a nonclathrin endocytic pathway: membrane cargo and lipid requirements. Mol Biol Cell. 2004;15:3542-52

33. D'Souza-Schorey C, Li G, Colombo M, Stahl P. A regulatory role for ARF6 in receptor-mediated endocytosis. Science. 1995:267:1175-8.

34. Kaplan G. Differences in the mode of phagocytosis with Fc and C3 receptors in macrophages. Scand J Immunol. 1977;6:797-807.

35. Botelho RJ, Grinstein S. Phagocytosis. Curr Biol. 2011;21:R533-8.

36. Pratten MK, Lloyd JB. Pinocytosis and phagocytosis: the effect of size of a particulate substrate on its mode of capture by rat peritoneal macrophages cultured in vitro. Biochim Biophys Acta Bba Gen Subj. 1986;881:307-13.

37. Tabata Y, Ikada Y. Effect of the size and surface charge of polymer microspheres on their phagocytosis by macrophage. Biomaterials 1988;9:356-62.

38. Koval M, Preiter K, Adles C, Stahl PD, Steinberg TH. Size of IgG-opsonized particles determines macrophage response during internalization. Exp Cell Res. 1998:242:265-73.

39. Champion JA, Walker A, Mitragotri S. Role of particle size in phagocytosis of polymeric microspheres. Pharmaceut Res. 2008;25:1815-21.

40. Churchward MA, Todd KG. Statin treatment affects cytokine release and phagocytic activity in primary cultured microglia through two separable mechanisms. Mol Brain. 2014;7:85.

41. Bryan AM, Farnoud AM, Mor V, Poeta MD. Macrophage cholesterol depletion and its effect on the phagocytosis of Cryptococcus neoformans. J Vis Exp. 2014. https://doi.org/10.3791/52432.

42. Gold ES, et al. Dynamin 2 Is required for phagocytosis in macrophages. J Exp Med. 1999;190:1849-56.

43. Metchnikoff, E. Untersuchungen über die mesodermalen Phagocyten einiger Wirbeltiere. Biologisches centralblatt 560-565 (1883).

44. Boucrot $\mathrm{E}$, et al. Endophilin marks and controls a clathrin-independent endocytic pathway. Nature. 2015;517:460-5.

45. Casamento A, Boucrot E. Molecular mechanism of fast endophilinmediated endocytosis. Biochem J. 2020;477:2327-45.

46. Clayton EL, Cousin MA. The molecular physiology of activity-dependent bulk endocytosis of synaptic vesicles. J Neurochem. 2009;111:901-14.

47. Kokotos AC, Low DW. Myosin II and dynamin control actin rings to mediate fission during activity-dependent bulk endocytosis. J Neurosci. 2015;35:8687-8

48. Nicholson-Fish JC, Kokotos AC, Gillingwater TH, Smillie KJ, Cousin MA VAMP4 is an essential cargo molecule for activity-dependent bulk endocytosis. Neuron. 2015;88:973-84.

49. Bonanomi $\mathrm{D}$, et al. Identification of a developmentally regulated pathway of membrane retrieval in neuronal growth cones. J Cell Sci. 2008;121:3757-69.

50. Clayton EL, et al. The phospho-dependent dynamin-syndapin interaction triggers activity-dependent bulk endocytosis of synaptic vesicles. J Neurosci. 2009;29:7706-17.

51. Marxen M, Volknandt W, Zimmermann H. Endocytic vacuoles formed following a short pulse of $\mathrm{K}+$-stimulation contain a plethora of presynaptic membrane proteins. Neuroscience. 1999:94:985-96.

52. Watanabe $\mathrm{S}$, et al. Ultrafast endocytosis at mouse hippocampal synapses. Nature. 2013:504:242-7.

53. Watanabe S, Boucrot E. Fast and ultrafast endocytosis. Curr Opin Cell Biol. 2017:47:64-71

54. Yue $\mathrm{H}, \mathrm{Xu}$ J. Cholesterol regulates multiple forms of vesicle endocytosis at a mammalian central synapse. J Neurochem. 2015;134:247-60.

55. Watanabe $\mathrm{S}$, et al. Ultrafast endocytosis at Caenorhabditis elegans neuromuscular junctions. Elife. 2013;2:e00723.
56. Hilgemann DW, Lin M-J, Fine M, Deisl C. On the existence of endocytosis driven by membrane phase separations. Biochim Biophys Acta Bba Biomembr. 2019:1862:183007.

57. Fine $M$, et al. Massive endocytosis driven by lipidic forces originating in the outer plasmalemmal monolayer: a new approach to membrane recycling and lipid domainsAmphipath-activated massive endocytosis. J Gen Physiol. 2011:137:137-54.

58. Hilgemann DW, Fine M, Linder ME, Jennings BC, Lin M-J. Massive endocytosis triggered by surface membrane palmitoylation under mitochondrial control in BHK fibroblasts. Elife. 2013;2:e01293.

59. Lariccia $\vee$, et al. Massive calcium-activated endocytosis without involvement of classical endocytic proteins. J Gen Physiol. 2011;137:111-32

60. Kerr MC, Teasdale RD. Defining macropinocytosis. Traffic. 2009;10:364-71.

61. Lim JP, Gleeson PA. Macropinocytosis: an endocytic pathway for internalising large gulps. Immunol Cell Biol. 2011;89:836-43.

62. Cardarelli F, Pozzi D, Bifone A, Marchini C, Caracciolo G. Cholesteroldependent macropinocytosis and endosomal escape control the transfection efficiency of lipoplexes in $\mathrm{CHO}$ living cells. Mol Pharmaceut. 2012;9:334-40.

63. Grimmer S, van Deurs B, Sandvig K. Membrane ruffling and macropinocytosis in A431 cells require cholesterol. J Cell Sci. 2002;115:2953-62.

64. Lewis WH. Pinocytosis. Johns Hopkins Hosp Bull 1931;17-27.

65. Pearse BM. Clathrin: a unique protein associated with intracellular transfer of membrane by coated vesicles. Proc Natl Acad Sci. 1976;73:1255-9.

66. Kaksonen M, Roux A. Mechanisms of clathrin-mediated endocytosis. Nat Rev Mol Cell Bio. 2018;19:313-26.

67. Rusk N, et al. Synaptojanin 2 functions at an early step of clathrin-mediated endocytosis. Curr Biol. 2003;13:659-63.

68. Taylor MJ, Perrais D, Merrifield CJ. A high precision survey of the molecular dynamics of mammalian clathrin-mediated endocytosis. Plos Biol. 2011;9:e1000604

69. Bitsikas V, Corrêa IR, Nichols BJ. Clathrin-independent pathways do not contribute significantly to endocytic flux. Elife. 2014;3:e03970.

70. Doherty GJ, McMahon HT. Mechanisms of endocytosis. Biochemistryus. 2009:78:857-902.

71. Cheng Z-J, et al. Distinct mechanisms of clathrin-independent endocytosis have unique sphingolipid requirements. Mol Biol Cell. 2006;17:3197-210.

72. Kovtun O, Tillu VA, Ariotti N, Parton RG, Collins BM. Cavin family proteins and the assembly of caveolae. J Cell Sci. 2015;128:1269-78.

73. Chidlow JH, Sessa WC. Caveolae, caveolins, and cavins: complex control of cellular signalling and inflammation. Cardiovasc Res. 2010;86:219-25.

74. Mayor S, Parton RG, Donaldson JG. Clathrin-independent pathways of endocytosis. Csh Perspect Biol. 2014;6:a016758.

75. Gupta GD, et al. Analysis of endocytic pathways in drosophila cells reveals a conserved role for GBF1 in internalization via GEECs. PLoS ONE. 2009;4:e6768.

76. Rivera-Milla E, Stuermer CAO, Málaga-Trillo E. Ancient origin of reggie (flotillin), reggie-like, and other lipid-raft proteins: convergent evolution of the SPFH domain. Cell Mol Life Sci Cmls. 2006:63:343-57.

77. Liu J, DeYoung SM, Zhang M, Dold LH, Saltiel AR. The stomatin/prohibitin/flotillin/HflK/C domain of flotillin-1 contains distinct sequences that direct plasma membrane localization and protein interactions in 3T3-L1 adipocytes. J Biol Chem. 2005;280:16125-34.

78. Morrow IC, et al. Flotillin-1/Reggie-2 traffics to surface raft domains via a novel Golgi-independent pathway identification of a novel membrane targeting domain and a role for palmitoylation. J Biol Chem. 2002;277:48834-41.

79. Solis GP, et al. Reggie/flotillin proteins are organized into stable tetramers in membrane microdomains. Biochem J. 2007;403:313-22.

80. Frick $M$, et al. Coassembly of flotillins induces formation of membrane microdomains, membrane curvature, and vesicle budding. Curr Biol. 2007;17:1151-6.

81. Otto GP, Nichols BJ. The roles of flotillin microdomains-endocytosis and beyond. J Cell Sci. 2011;124:3933-40.

82. Schweitzer JK, Sedgwick AE, D'Souza-Schorey C. ARF6-mediated endocytic recycling impacts cell movement, cell division and lipid homeostasis. Semin Cell Dev Biol. 2011;22:39-47. 
83. Honda A, et al. Phosphatidylinositol 4-phosphate 5-kinase a is a downstream effector of the small g protein arf6 in membrane ruffle formation. Cell. 1999;99:521-32.

84. Donaldson JG, Johnson DL, Dutta D. Rab and Arf G proteins in endosomal trafficking and cell surface homeostasis. Small Gtpases. 2016;7:247-51.

85. Lau AW, Chou MM. The adaptor complex AP-2 regulates post-endocytic trafficking through the non-clathrin Arf6-dependent endocytic pathway. J Cell Sci. 2008;121:4008-17

86. Okada R, et al. Activation of the small G protein Arf6 by dynamin2 through guanine nucleotide exchange factors in endocytosis. Sci RepUK. 2015:5:14919.

87. Rosales C, Uribe-Querol E. Phagocytosis: a fundamental process in immunity. Biomed Res Int. 2017;2017:1-18.

88. Tohyama Y, Yamamura H. Protein tyrosine kinase, Syk: a key player in phagocytic cells. J Biochem. 2009;145:267-73.

89. Gillooly DJ, Simonsen A, Stenmark H. Phosphoinositides and phagocytosis. J Cell Biol. 2001:155:15-8.

90. Swanson JA, Yoshida S. Encyclopedia of cell biology 2016;758-765. https://doi.org/10.1016/b978-0-12-394447-4.20084-9.

91. King JS, Kay RR. The origins and evolution of macropinocytosis. Philos Trans R Soc B. 2019:374:20180158.

92. West MA, Bretscher MS, Watts C. Distinct endocytotic pathways in epidermal growth factor-stimulated human carcinoma A431 cells. J Cell Biol. 1989;109:2731-9.

93. Moreau HD, et al. Macropinocytosis overcomes directional bias in dendritic cells due to hydraulic resistance and facilitates space exploration. Dev Cell. 2019;49:171-188.e5.

94. Li Y, et al. Macropinocytosis-mediated membrane recycling drives neural crest migration by delivering F-actin to the lamellipodium. Proc Natl Acad Sci. 2020;117:27400-11.

95. Recouvreux MV, Commisso C. Macropinocytosis: a metabolic adaptation to nutrient stress in cancer. Front Endocrinol. 2017:8:261.

96. Commisso C, et al. Macropinocytosis of protein is an amino acid supply route in Ras-transformed cells. Nature. 2013:497:633-7.

97. Commisso C, Debnath J. Macropinocytosis fuels prostate cancer. Cancer Discov. 2018;8:800-2.

98. Charpentier JC, et al. Macropinocytosis drives T cell growth by sustaining the activation of mTORC1. Nat Commun. 2020;11:180

99. Milosevic I, et al. Recruitment of endophilin to clathrin-coated pit necks is required for efficient vesicle uncoating after fission. Neuron. 2011:72:587-601.

100. Kessels MM, Qualmann B. Syndapins integrate N-WASP in receptormediated endocytosis. Embo J. 2002;21:6083-94.

101. Chanaday NL, Cousin MA, Milosevic I, Watanabe S, Morgan JR. The synaptic vesicle cycle revisited: new insights into the modes and mechanisms. J Neurosci. 2019;39:8209-16.

102. Watanabe $\mathrm{S}$, et al. Synaptojanin and endophilin mediate neck formation during ultrafast endocytosis. Neuron. 2018;98:1184-1197.e6.

103. Bacia K, Schwille P, Kurzchalia T. Sterol structure determines the separation of phases and the curvature of the liquid-ordered phase in model membranes. Proc Natl Acad Sci USA. 2005;102:3272-7.

104. Qureshi OS, et al. Trans-endocytosis of CD80 and CD86: a molecular basis for the cell-extrinsic function of CTLA-4. Science. 2011;332:600-3.

105. Qureshi OS, et al. Constitutive clathrin-mediated endocytosis of CTLA-4 persists during T cell activation. J Biol Chem. 2012;287:9429-40.

106. Monjas A, Alcover A, Alarcón B. Engaged and bystander T cell receptors are down-modulated by different endocytotic pathways. J Biol Chem. 2004;279:55376-84

107. Crotzer VL, Mabardy AS, Weiss A, Brodsky FM. T Cell receptor engagement leads to phosphorylation of clathrin heavy chain during receptor internalization. J Exp Med. 2004;199:981-91.

108. Łyszkiewicz M, et al. Human FCHO1 deficiency reveals role for clathrinmediated endocytosis in development and function of T cells. Nat Commun. 2020;11:1031.

109. Rossatti $P$, et al. Cdc42 couples T cell receptor endocytosis to GRAF1mediated tubular invaginations of the plasma membrane. Cells. 2019;8:1388.

110. Compeer EB, et al. A mobile endocytic network connects clathrinindependent receptor endocytosis to recycling and promotes $T$ cell activation Nat Commun. 2018:9:1597.
111. Lamaze C, et al. Interleukin 2 receptors and detergent-resistant membrane domains define a clathrin-independent endocytic pathway. Mol Cell. 2001:7:661-71.

112. Johnson DL, Wayt J, Wilson JM, Donaldson JG. Arf6 and Rab22 mediate T cell conjugate formation by regulating clathrin-independent endosomal membrane trafficking. J Cell Sci. 2017;130:jcs.200477.

113. Wu Y, et al. Human $\gamma \delta T$ cells: a lymphoid lineage cell capable of professional phagocytosis. J Immunol. 2009;183:5622-9.

114. Zhu Y, et al. Human $\gamma \delta T$ cells augment antigen presentation in listeria monocytogenes infection. Mol Med. 2016;22:737-46.

115. Martínez-Martín N, et al. T Cell receptor internalization from the immunological synapse is mediated by TC21 and RhoG GTPase-dependent phagocytosis. Immunity. 2011;35:208-22.

116. Yellin MJ, et al. CD40 molecules induce down-modulation and endocytosis of T cell surface T cell-B cell activating molecule/CD40-L. Potential role in regulating helper effector function. J Immunol Baltim Md. 1994;1950(152):598-608.

117. Yu A, Olosz F, Choi CY, Malek TR. Efficient internalization of IL-2 depends on the distal portion of the cytoplasmic tail of the IL-2R common $y$-chain and a lymphoid cell environment. J Immunol. 2000;165:2556-62.

118. Basquin C, et al. The signalling factor PI3K is a specific regulator of the clathrin-independent dynamin-dependent endocytosis of IL-2 receptors. J Cell Sci. 2013;126:1099-108.

119. Rocca A, Lamaze C, Subtil A, Dautry-Varsat A. Involvement of the ubiquitin/proteasome system in sorting of the interleukin 2 receptor $\beta$ chain to late endocytic compartments. Mol Biol Cell. 2001;12:1293-301.

120. Yu A, Malek TR. The proteasome regulates receptor-mediated endocytosis of interleukin-2.J Biol Chem. 2001:276:381-5.

121. Hsu H, et al. WC1 Is a hybrid $\gamma \delta$ TCR coreceptor and pattern recognition receptor for pathogenic bacteria. J Immunol. 2015;194:2280-8.

122. Hsu H, Baldwin CL, Telfer JC. The endocytosis and signaling of the $\gamma \delta$ T cell coreceptor WC1 are regulated by a dileucine motif. J Immunol. 2015;194:2399-406.

123. D'Oro U, Vacchio MS, Weissman AM, Ashwell JD. Activation of the Lck tyrosine kinase targets cell surface $T$ cell antigen receptors for lysosomal degradation. Immunity. 1997;7:619-28.

124. Lauritsen JP, et al. Two distinct pathways exist for down-regulation of the TCR. J Immunol Baltim Md. 1998;1950(161):260-7.

125. Calzoni $\mathrm{E}$, et al. F-BAR domain only protein 1 (FCHO1) deficiency is a novel cause of combined immune deficiency in humans. J Allergy Clin Immun. 2019:143:2317-2321.e12.

126. McGavin MKH, et al. The intersectin 2 adaptor links wiskott aldrich syndrome protein (WASp)-mediated actin polymerization to T cell antigen receptor endocytosis. J Exp Med. 2001;194:1777-87.

127. Onnis A, Baldari CT. Orchestration of Immunological synapse assembly by vesicular trafficking. Front Cell Dev Biol. 2019;7:110.

128. Evnouchidou l, et al. IRAP-dependent endosomal T cell receptor signalling is essential for T cell responses. Nat Commun. 2020;11:2779.

129. José ES, Borroto A, Niedergang F, Alcover A, Alarcón B. Triggering the TCR complex causes the downregulation of nonengaged receptors by a signal transduction-dependent mechanism. Immunity. 2000;12:161-70.

130. Willinger T, Staron M, Ferguson SM, Camilli PD, Flavell RA. Dynamin 2-dependent endocytosis sustains T-cell receptor signaling and drives metabolic reprogramming in T lymphocytes. Proc Natl Acad Sci. 2015;112:4423-8.

131. Prieto-Sánchez RM, Berenjeno IM, Bustelo XR. Involvement of the Rho/Rac family member RhoG in caveolar endocytosis. Oncogene. 2006:25:2961-73.

132. Bras SL, et al. Recruitment of the actin-binding protein HIP-55 to the immunological synapse regulates $T$ cell receptor signaling and endocytosis. J Biol Chem. 2004;279:15550-60.

133. Iseka FM, et al. Role of the EHD family of endocytic recycling regulators for TCR recycling and T cell function. J Immunol. 2018;200:483-99.

134. Rajendran $L$, et al. Asymmetric localization of flotillins/reggies in preassembled platforms confers inherent polarity to hematopoietic cells. Proc Natl Acad Sci. 2003;100:8241-6.

135. Redpath $\mathrm{GMI}$, et al. Flotillins promote $T$ cell receptor sorting through a fast Rab5-Rab11 endocytic recycling axis. Nat Commun. 2019:10:4392. 
136. Ahmed KA, Munegowda MA, Xie Y, Xiang J. Intercellular trogocytosis plays an important role in modulation of immune responses. Cell Mol Immunol. 2008;5:261-9.

137. Rosenits K, Keppler SJ, Vucikuja S, Aichele P.T cells acquire cell surface determinants of APC via in vivo trogocytosis during viral infections. Eur J Immunol. 2010;40:3450-7.

138. Reed J, Wetzel SA. Trogocytosis-mediated intracellular signaling in CD4 + T cells drives T H 2-associated effector cytokine production and differentiation. J Immunol. 2019;202:2873-87.

139. Dhainaut $M$, Moser $M$. Regulation of immune reactivity by intercellular transfer. Front Immunol. 2014;5:112.

140. Miyake K, et al. Trogocytosis of peptide-MHC class II complexes from dendritic cells confers antigen-presenting ability on basophils. Proc Natl Acad Sci. 2017;114:1111-6.

141. Mao Y, Finnemann SC. Regulation of phagocytosis by Rho GTPases. Small Gtpases. 2015;6:89-99.

142. Chaudhri $\mathrm{G}$, et al. $T$ cell receptor sharing by cytotoxic T lymphocytes facilitates efficient virus control. Proc Natl Acad Sci. 2009;106:14984-9.
143. Hamieh M, et al. CART cell trogocytosis and cooperative killing regulate tumour antigen escape. Nature. 2019;568:112-6.

144. Ren W, et al. Amino-acid transporters in T-cell activation and differentiation. Cell Death Dis. 2017;8:e2655-e2655.

145. Milkereit R, et al. LAPTM4b recruits the LAT1-4F2hc Leu transporter to lysosomes and promotes mTORC1 activation. Nat Commun. 2015;6:7250.

146. Hayashi $K$, Jutabha P, Endou H, Sagara H, Anzai N. LAT1 is a critical transporter of essential amino acids for immune reactions in activated human T Cells. J Immunol. 2013;191:4080-5.

\section{Publisher's Note}

Springer Nature remains neutral with regard to jurisdictional claims in published maps and institutional affiliations.
Ready to submit your research? Choose BMC and benefit from:

- fast, convenient online submission

- thorough peer review by experienced researchers in your field

- rapid publication on acceptance

- support for research data, including large and complex data types

- gold Open Access which fosters wider collaboration and increased citations

- maximum visibility for your research: over $100 \mathrm{M}$ website views per year

At BMC, research is always in progress.

Learn more biomedcentral.com/submissions 